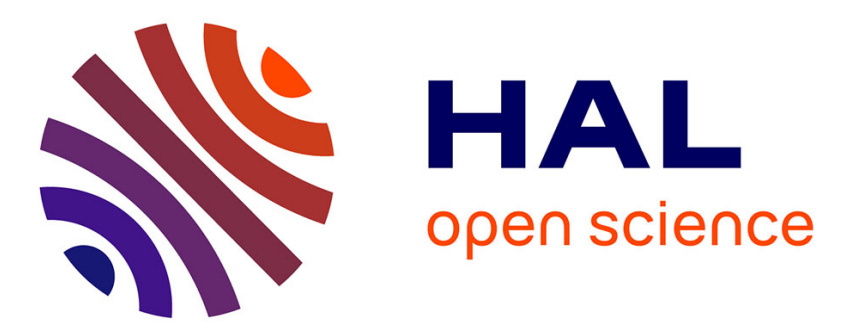

\title{
Surface oxidation of nickel base alloys and stainless steel under pure oxygen atmosphere: Application to oxygen safety
}

Frédéric Coste, Martina Ridlová, Nicolas Gallienne, Jacques Quintard, Gabriel Bert

\section{To cite this version:}

Frédéric Coste, Martina Ridlová, Nicolas Gallienne, Jacques Quintard, Gabriel Bert. Surface oxidation of nickel base alloys and stainless steel under pure oxygen atmosphere: Application to oxygen safety. Journal of Laser Applications, 2019, 31 (2), pp.Article number 022518. 10.2351/1.5096149 . hal02174755

\section{HAL Id: hal-02174755 \\ https://hal.science/hal-02174755}

Submitted on 11 Jul 2019

HAL is a multi-disciplinary open access archive for the deposit and dissemination of scientific research documents, whether they are published or not. The documents may come from teaching and research institutions in France or abroad, or from public or private research centers.
L'archive ouverte pluridisciplinaire HAL, est destinée au dépôt et à la diffusion de documents scientifiques de niveau recherche, publiés ou non, émanant des établissements d'enseignement et de recherche français ou étrangers, des laboratoires publics ou privés. 


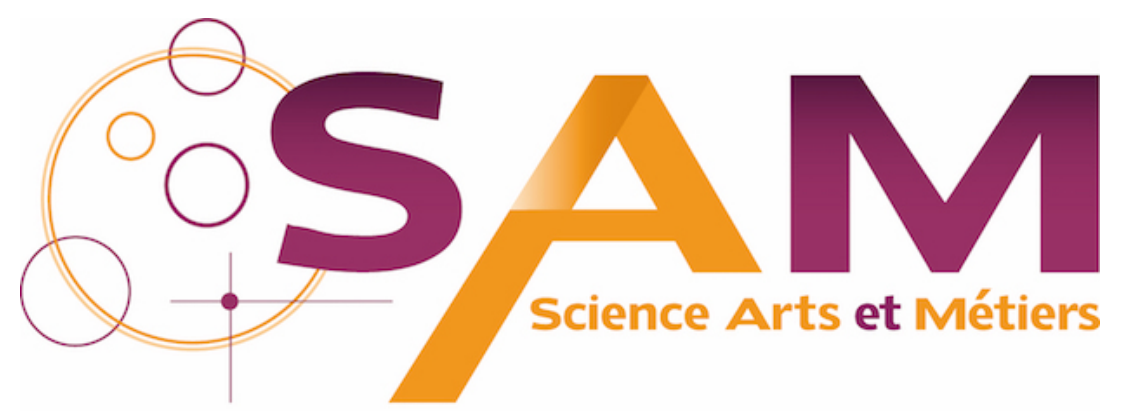

Archive Ouverte - Open Repository

\section{Science Arts \& Métiers (SAM)}

is an open access repository that collects the work of Arts et Métiers ParisTech researchers and makes it freely available over the web where possible.

This is an author-deposited version published in: https://sam.ensam.eu Handle ID: .http://hdl.handle.net/10985/15617

\section{To cite this version :}

Frédéric COSTE, Martina RIDLOVÁ, Nicolas GALLIENNE, Gabriel BERT, Jacques QUINTARD Surface oxidation of nickel base alloys and stainless steel under pure oxygen atmosphere: Application to oxygen safety - Journal of Laser Applications - Vol. Volume 31, Issue 2,, p.Article number $022518-2019$ 


\title{
Surface oxidation of nickel base alloys and stainless steel under pure oxygen atmosphere: Application to oxygen safety
}

doi: $10.2351 / 1.5096149$

Frédéric Coste, ${ }^{7}$ (D) Martina Ridlova, ${ }^{2}$ Nicolas Gallienne, ${ }^{2}$ Jacques Quintard, ${ }^{2}$ and Gabriel Bert ${ }^{2}$

\author{
AFFILIATIONS \\ 'PIMM Laboratory, Ensam, CNRS, Cnam, HESAM University, 151 Boulevard de l'Hôpital, 75013 Paris, France \\ ${ }^{2}$ Air Liquide Research and Development, 1 Chemin de la Porte des Loges, Jouy-en-Josas 78354, France
}

\begin{abstract}
Irradiation by a high power laser beam has been used since several years as an innovative approach for evaluating the reactivity of metallic materials with a pure oxygen atmosphere. Indeed, materials selection for oxygen service is a key factor of mitigating the ignition of equipment also called as oxygen fire. Pulled by the need having always more efficient industrial processes, the oxygen usages are evolving toward steadily higher pressures or temperatures. In such operating conditions, the evaluation of the metallic materials resistance to the oxygen fire ignition and their property to propagate based on the oxidation kinetic is the only way to avoid the oversizing of equipment. In this context, the use of laser in evaluating the reactivity of metallic materials is a well-adapted method enabling the accurate control of the energy deposition transmitted to the tested material during oxidation as well as giving access to the energy threshold required to trigger the oxygen fire ignition. This paper investigates the oxidation kinetics on nickel-based alloys (Inconels 600 and 625) and on stainless steel 310, using a laser or a furnace preheating on small metallic parts. The scope of the study is the oxidation step taking place before the heating of the sample up to its ignition temperature. Process parameters are oxygen pressure (1 and $40 \mathrm{barg}$ ), oxygen content (air versus pure oxygen), duration, and temperature. A numerical model is used to couple a sample surface condition (machined, sandblasted, polished) with laser parameters (power, duration) needed to reach a predetermined preheating temperature of the sample. In order to determine the threshold heat input for materials' ignition by a laser in the oxygen atmosphere, it is necessary to know the absorption coefficient of the laser at the sample surface. This parameter is measured for various oxide layer thicknesses.
\end{abstract}

Key words: laser surface treatment, surface oxidation, absorptivity, oxygen

https://doi.org/10.2351/1.5096149

\section{INTRODUCTION}

The prevention of oxygen fire is a constant preoccupancy of the oxygen industry, especially in the current context of the evolution of operating conditions toward higher pressure or temperature.

This study on the generation of an oxide layer on stainless steel and nickel base alloys using a laser is a part of a larger research project dedicated to the ignition and combustion of metallic parts under pure gaseous oxygen which is in a relationship with industrial oxygen safety.

The use of a laser source to initiate combustion of a metallic part has been demonstrated for now more than ten years. ${ }^{1-4}$ The major advantage of laser compared with other heat inputs, e.g., pyrotechnical promoters, is the precise control of the thermal energy deposition on the tested sample. Laser power, spot size, and duration of laser irradiation are fully controlled and modular. These advantages allow determining, with a high level of accuracy, the minimum energy required to trigger the combustion of a given material as well as the minimum temperature to ignite material. ${ }^{1}$ This last feature is out of the scope of this paper.

In order to determine the minimum energy for ignition, it is necessary to know the laser characteristics (power, duration, spot diameter, energy repartition on laser spot area, a large spot, and 
low power density is chosen to avoid reaching evaporation temperature during ignition and offer a better control of preheating) as well as the value of the absorption coefficient of the laser beam at the sample surface; this represents the fraction of laser energy actually transferred to the sample relative to the total energy delivered by the laser.

All along the heating sequence of the metallic sample by the laser under a pure oxygen atmosphere, the sample surface evolves leading to an unsteady absorption coefficient. It has been observed that the coefficient value at the end of the heating sequence can be up to two times the initial one (see Table III).

Consequently, it is impossible to determine the total energy absorbed by the sample before ignition without knowing the absorption coefficient according to the time. In order to solve this issue, a preliminary oxidation step has been developed so that to generate an oxide layer having a stable and homogeneous absorption coefficient all along the heating sequence up to the ignition temperature. Thereby, the integration of the portion of the laser energy absorbed as of the beginning of the ignition sequence is possible and gives access to the total energy absorbed by the sample before ignition.

Another objective of the preliminary oxidation step is to obtain a surface state having a chemical composition close to that of industrial equipment exposed to a heated gaseous oxygen atmosphere. This allows one to consider that the minimum ignition energy determined by laser irradiation is representative to the energy required to trigger the combustion in a real life industrial configuration.

This paper focuses on the temporal evolution of surface state of metallic samples during the preliminary oxidation step, in the presence of oxidizing atmosphere of air (at pressure 1 bar) or oxygen (purity at least $99.5 \% \mathrm{O}_{2}$ at pressures 1 and $40 \mathrm{barg}$ ), for three metallic alloys (Inconels 600, 625 and stainless steel 310) with three initial surface conditions (machined, sandblasted by corundum, polished with P120). A numerical model is used to couple the sample surface condition with laser parameters (power, duration) and oxygen operation conditions (pressure) required to reach the set preheating temperature of the sample. It gives the maximum temperature reached on the sample in contact with oxygen during preheating by laser. Moreover, the problematics of thermal losses induced by the presence of a high pressure gaseous oxygen atmosphere is discussed.

Finally, the oxide layers are characterized in terms of thickness, chemical composition, and value of absorption coefficient laser/sample.

\section{STUDIED MATERIALS}

The study is carried out on three materials: stainless steel 310 , Inconel 600, and Inconel 625. The sample's geometry is a disc of $25.4 \mathrm{~mm}$ in diameter and $3 \mathrm{~mm}$ in thickness.

\section{EXPERIMENTAL SETUP}

The study of metals' ignition and combustion under an oxygen atmosphere requires specific safety considerations. The pressure vessel (Fig. 1) used for experiments allows one to ignite and to propagate the combustion through different geometries of samples. For the need of the present study, the use of pressure vessel is limited to the preheating of the disc-type samples.

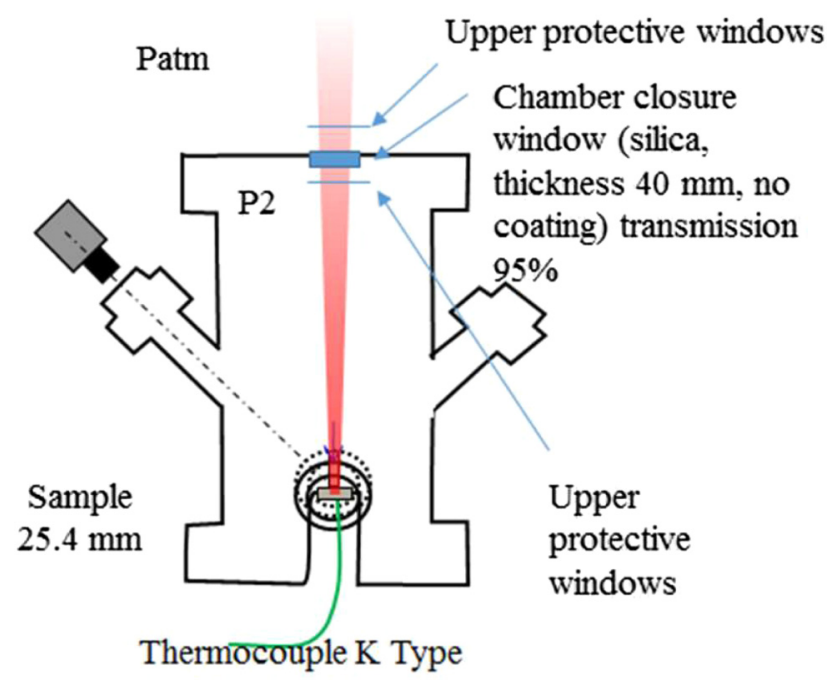

FIG. 1. Pressure vessel for experiments with a pressurized gaseous oxygen atmosphere.

The pressure vessel has a volume of 111 and allows working in the gaseous oxygen atmosphere under various conditions of oxygen velocity and sample temperature. The inner side of the pressure vessel is jacketed by a copper liner in order to prevent impacts of burning particles on the wall of the pressure vessel. One window (in upper flange) is dedicated for the laser beam input, two windows with a $45^{\circ}$ incidence allow visualization, and two additional windows with a $180^{\circ}$ incidence can be used for lateral views. The setup allows working in a static atmosphere or under a gas flow (e.g., up to $40 \mathrm{~m} / \mathrm{s}$ under $40 \mathrm{barg}$, with a nozzle diameter equal to $4 \mathrm{~mm}$ ). Five type $\mathrm{K}$ thermocouples (diameter $200 \mu \mathrm{m}$, see Fig. 2) are used to measure the temperature on the back side of the sample that remains contact with ambient pressure air.

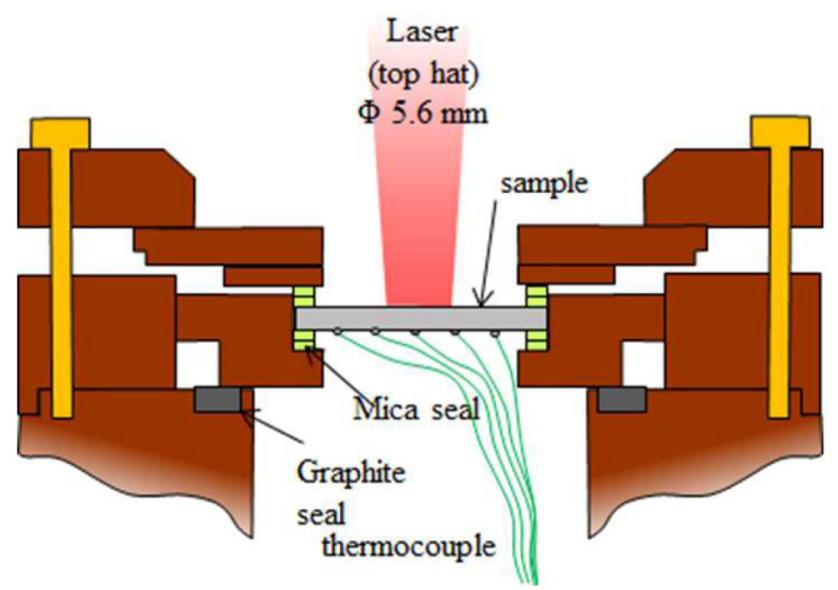

FIG. 2. Geometry of the sample holder. 
A $2 \mathrm{~kW}$ diode laser from Laserline (type LDM 2000-60) emitting at a central wavelength of $950 \mathrm{~nm}$ is used, and this choice is discussed hereafter. A long focal length allows reaching inside the pressure vessel a laser spot size of $5.6 \mathrm{~mm}$ diameter. The focusing head is mounted on a 6 axis anthropomorphic arm robot, which allows the precise control of the positioning of the laser spot inside and outside the pressure vessel as well as to move the laser spot during the preheating step, in order to obtain a homogeneous temperature repartition inside the sample. Afterward, for materials resistance determination to oxygen fire ignition, the robot moves and focuses the laser spot to the center of the oxidized sample.

\section{A. Oxygen compatible seal of sample holder}

Disc samples are a part of the pressure vessel, with the upper side in contact with the pressurized oxygen atmosphere and the bottom side in contact with ambient air. The sealing at interface sample/pressure vessel was a challenging point as it has to be compatible with high pressure oxygen, meet the sealing requirements, and minimize the heat losses by conduction between the sample and the pressure vessel.

The found original solution was to use Mica based seals. More than being compatible with the oxygen atmosphere, Mica offers a rather good thermal barrier (thermal conductivity of $3 \mathrm{~W} \mathrm{~m}^{-1} \mathrm{~K}^{-1}$ ) and performs under mechanical loading better than ceramic seals. Furthermore, this item is also consumable (it has to be replaced after each test) and the cheap cost of Mica is well-adapted to a high consumption of sealing rings. Consequently, the sealing rings laser cut in Mica plates was selected for the present experimental study.

\section{B. Laser beam analyses in pressurized oxygen}

A preliminary study of metallic sample ignition by laser irradiation was done in the gaseous oxygen atmosphere using a standard rod laser lamp pumped at a wavelength of $1064 \mathrm{~nm}$. This configuration gave coherent results from ambient pressure up to $10 \mathrm{barg}$, but results observed for a higher oxygen pressure were not in agreement with those expected-the minimum ignition energy for triggering sample ignition determined at oxygen pressure inferior to $10 \mathrm{barg}$ was not enough to produce ignition of samples at an oxygen pressure of 40 barg.

As Greenblatt et al. $^{2}$ measured in 1990 an absorption spectrum of a 55 bars oxygen atmosphere at a wavelength around 1100 $\mathrm{nm}$ (Fig. 3), we developed a focus beam monitor, compatible with the pressurized oxygen atmosphere to visualize the shape of the laser beam, inside a chamber, for various oxygen pressures. A silica substrate, frosted glass, inside the chamber is observed with the help of a high speed camera in order to visualize the temporal evolution of the spot size during the laser shot.

Characterization of the laser spot diameter evolution was done at different oxygen pressures from ambient to 120 barg and using several lasers emitting, respectively, at 902, 932, 962, 1012, and $1064 \mathrm{~nm}$, with the path length propagation in pure oxygen in the range of $220 \mathrm{~mm}$. Table I illustrates that all tested wavelengths show an absorption affect except the $962 \mathrm{~nm}$.

The observed behavior can be explained by considering that for a high power laser, even a small absorption along the laser propagation path in pressurized gaseous oxygen leads to a thermal

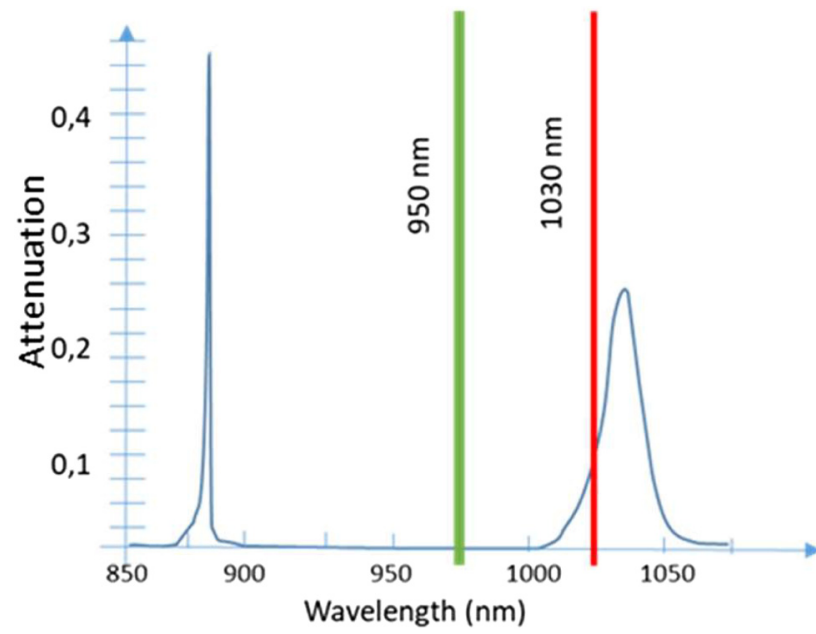

FIG. 3. Absorption spectrum of a 55 bars oxygen atmosphere, in the range 850-1050 nm, from Ref. 2.

lenses effect that will affect the laser beam focusing behavior. This explains the strong evolution of the spot size for the $1064 \mathrm{~nm}$ wavelength.

Despite the work of Greenblatt et al. ${ }^{2}$ that does not show any absorption between 800 and $1000 \mathrm{~nm}$ wavelength, the spectral window allowing high power laser beam propagation without thermal lenses effect in high pressure pure oxygen is limited to the range around $960 \mathrm{~nm}$. Consequently, the wavelength $950 \mathrm{~nm}$ delivered by $2 \mathrm{~kW}$ Laserline diode was chosen for the present study.

\section{ABSORPTION COEFFICIENT CHARACTERIZATION}

A conventional way ${ }^{5,6}$ for the determination of the surface absorption coefficient for a specific laser wavelength consists in the use of an integrating sphere (Ulbricht sphere). The internal surface of the integrating sphere is sandblasted and coated with $\mathrm{BaSO}_{4}$ for a good diffusion and reflectivity of the light inside. The reflected light is characterized with a standard photodiode covered with an interferential filter, centered on the laser's line wavelength.

TABLE I. Laser spot diameter evolution in pressurized oxygen at 100 or 40 barg [for $950 \mathrm{~nm}$ and $962 \mathrm{~nm}$ (in boldface), laser spot diameter remains constant].

\begin{tabular}{lccr}
\hline $\begin{array}{l}\text { Laser } \\
\text { wavelength } \\
(\mathrm{nm})\end{array}$ & $\begin{array}{c}\text { Initial spot } \\
\text { diameter } \\
(\mathrm{mm})\end{array}$ & $\begin{array}{c}\text { Spot diam. } \\
\text { after } 55 \mathrm{~ms} \\
(\mathrm{~mm})\end{array}$ & $\begin{array}{r}\text { Variation } \\
(\%)\end{array}$ \\
\hline 902 & 3.37 & 3.90 & 15.7 \\
932 & 3.40 & 3.60 & 5.9 \\
$\mathbf{9 5 0}$ & $\mathbf{5 . 6 0}$ & $\mathbf{5 . 6 0}$ & $\mathbf{0 . 0}$ \\
$\mathbf{9 6 2}$ & $\mathbf{3 . 4 0}$ & $\mathbf{3 . 4 0}$ & $\mathbf{0 . 0}$ \\
1012 & 3.50 & 4.60 & 31.4 \\
1064 & 2.00 & 5.00 & 150.0 \\
\hline \hline
\end{tabular}


A reference signal is defined using a reference sample (Fig. 4), with a known reflection (or absorption) coefficient. The surface to be characterized for absorption coefficient will reflect a specific level of signal intensity, and the ratio $\mathrm{R}=$ signal level/reference level will allow us to calculate the researched reflection (absorption) coefficient. The sum of reflection and absorption coefficients equals to 1 .

\section{A. Reference mirror characterization}

The reference surface is a copper mirror. We evaluate the absorption coefficient of this surface using a known energy deposition on the reflective side of the mirror and by a thermal camera measurement of the temperature elevation on the mirror's backside. The latter is covered with black paint, giving an emissivity equals to 1. The volume and the weight of the mirror are precisely known, and the mirror is maintained with two ceramic supports, in order to minimize conductive thermal losses. The relation between the absorbed energy and the measured temperature variation $(\Delta T)$ gives the absorbed energy [Eq. (1)], where $\rho$ stands for the density of copper and $\mathrm{Cp}$ for its heat capacity,

$$
E_{\text {absorbed }}=\rho \cdot \mathrm{Cp} \cdot \Delta T \text {. }
$$

Table II summarizes the average values from five trials with laser energy depositions of 1 and $2 \mathrm{~kJ}$, respectively, the resulting mirror temperature evolution and its resulting absorbed energy. To conclude, the reflexion coefficient of copper mirror is estimated to $98.5 \%$.

\section{B. Samples absorption coefficient characterization}

The absorption coefficient was determined for three materials: stainless steel 310, Inconel 600, and Inconel 625 having three surface states: machined, sandblasted, and polished on a vibrating plate with metallographic paper P120. Obtained absorption coefficient was compared with those measured after oxidation treatment done on

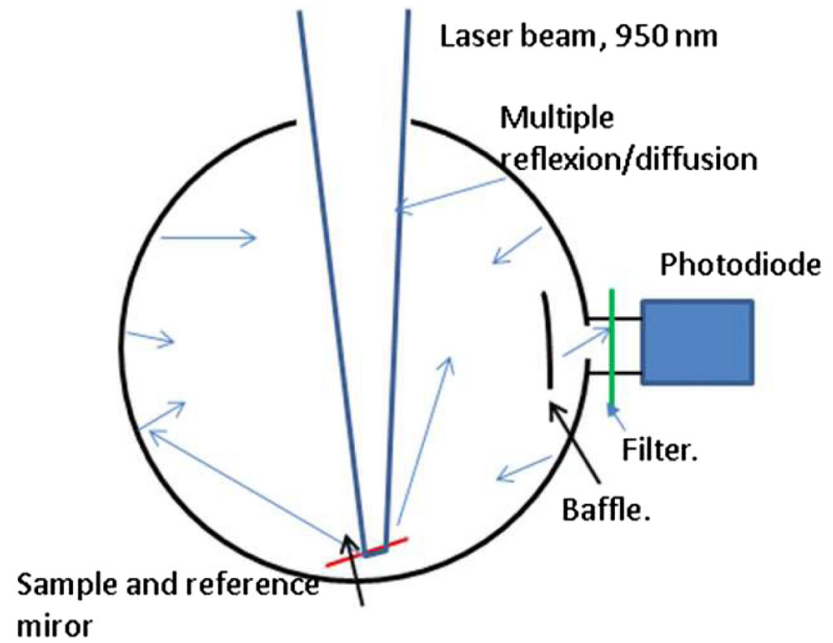

FIG. 4. Integrating sphere and sample position.
TABLE II. Copper mirror temperature evaluation for two energies' depositions.

\begin{tabular}{lcc}
\hline \hline $\begin{array}{l}\text { Laser energy } \\
\text { deposition } \\
(\mathrm{kJ})\end{array}$ & $\begin{array}{c}\text { Temperature } \\
\text { increase of mirror } \\
(\mathrm{K})\end{array}$ & $\begin{array}{c}\text { Absorbed energy } \\
\text { by mirror } \\
(\mathrm{J})\end{array}$ \\
\hline 1 & 4.0 & 13.4 \\
2 & 8.3 & 27.8 \\
\hline \hline
\end{tabular}

the aforementioned samples. The objective of oxidation treatment was to create a continuous and homogeneous oxide layer with an absorption coefficient close to 1 .

Sandblasting treatment by corundum appeared as a good solution to increase and homogenize the sample surface. After oxidation treatment, it allowed to create a regular oxide layer and to increase significantly the absorption coefficient. As shown in Table III, the measured absorption coefficient was $0.41 \pm 0.02$ for a machined surface and reached $0.62 \pm 0.02$ for a sandblasted surface (both in a nonoxidized state). After oxidation treatment (described hereafter), the absorption coefficient increased up to 0.92 for SS310.

As energy dispersive spectrometer (EDS) surface analysis revealed that some particles of corundum may remain fixed at the material surface (Fig. 5), the preferred method for sample surface preparation was the polishing on a vibrating plate with metallographic paper P120.

\section{EXPERIMENTAL AND NUMERICAL APPROACH}

The generation of the oxide layer on metallic samples (preheating cycle) is the first step in the methodology used for the determination of materials resistance to ignition and combustion in pure oxygen. During this preliminary oxidation step, the sample's temperature evolves from ambient to $850^{\circ} \mathrm{C}$ (measured at air side), at about $30^{\circ} \mathrm{C} / \mathrm{s}$ and during $30 \mathrm{~s}$. Tests were carried out using a laser power of $360 \mathrm{~W}$, with a top hat repartition, on a spot size of $5.6 \mathrm{~mm}$ diameter, with a magnification of 9.3 and using an optical fiber of $0.6 \mathrm{~mm}$ diameter.

The homogenization of the temperature in the sample is improved with the help of a rotating movement of the laser spot on the sample. The radius of the spot trajectory is $5 \mathrm{~mm}$, and the rotating speed is one turn per second. For temperature control, five thermocouples are welded on sample's back side (air side) as illustrated in Fig. 6.

We observed that after one $30 \mathrm{~s}$ cycle, the absorption coefficient of the sample surface reached its maximal and constant value. Consequently, such surface is ready for the determination of

TABLE III. Absorption coefficient of studied samples.

\begin{tabular}{lcccc}
\hline \hline & Machined & Sandblasted & P120 & Oxidized by laser \\
\hline SS310 & 0.43 & 0.65 & 0.50 & 0.92 \\
IN600 & 0.41 & 0.62 & 0.40 & 0.80 \\
IN625 & 0.40 & 0.64 & 0.52 & 0.86 \\
\hline
\end{tabular}



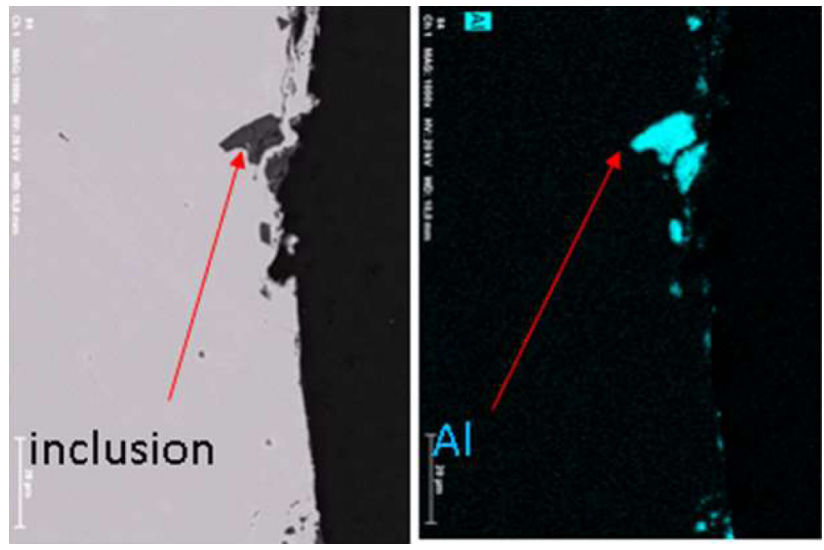

FIG. 5. SEM image $\times 1000$ by an EDS detector. Characterization of corundum particle on the sample surface after sandblasting.

sample ignition behavior in pure oxygen upon subsequent irradiation by a laser.

In order to facilitate the characterization of the oxide layers, we increased the time of laser preheating in oxygen to $900 \mathrm{~s}$ (at 1 and $40 \mathrm{barg}$ ). We also performed a comparative oxidation study in air at $850^{\circ} \mathrm{C}$ during up to $332 \mathrm{~h}$. Resulting oxidation kinetics as well as observed morphologies of formed oxides are presented in Sec. VI.

\section{A. Effect of pressure on thermal losses}

In order to determine the influence of oxygen pressure on sample thermal losses, two types of experiments were performed; first, a $30 \mathrm{~s}$ experiment that consisted of a laser heating at $850^{\circ} \mathrm{C}$ followed by a natural air cooling and then, a $1800 \mathrm{~s}$ experiment, when the sample was first laser heated to $850{ }^{\circ} \mathrm{C}$ and the laser power was modulated to hold $850^{\circ} \mathrm{C}$ for $1800 \mathrm{~s}$, followed by natural air cooling. In both cases, the sample temperature was controlled by five thermocouples at the air side of the sample (Fig. 6).

Figure 7 presents a typical evolution of sample temperature recorded by thermocouples during a $30 \mathrm{~s}$ preheating cycle in oxygen at 1 and $40 \mathrm{barg}$. Observed periodic oscillations of
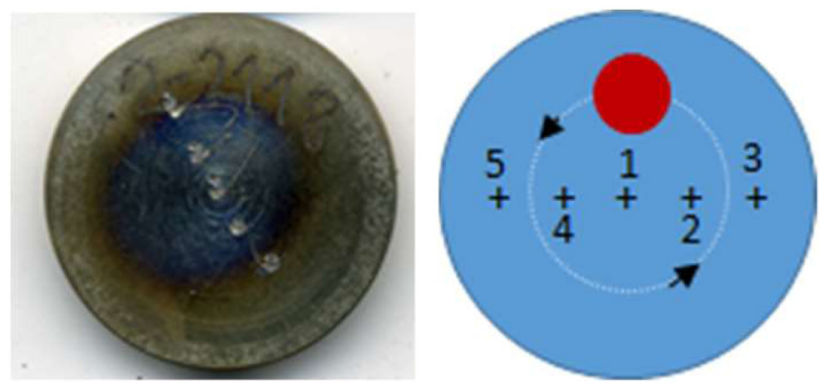

FIG. 6. Thermocouples' positions on the back side of the sample and laser spot trajectory (in red).

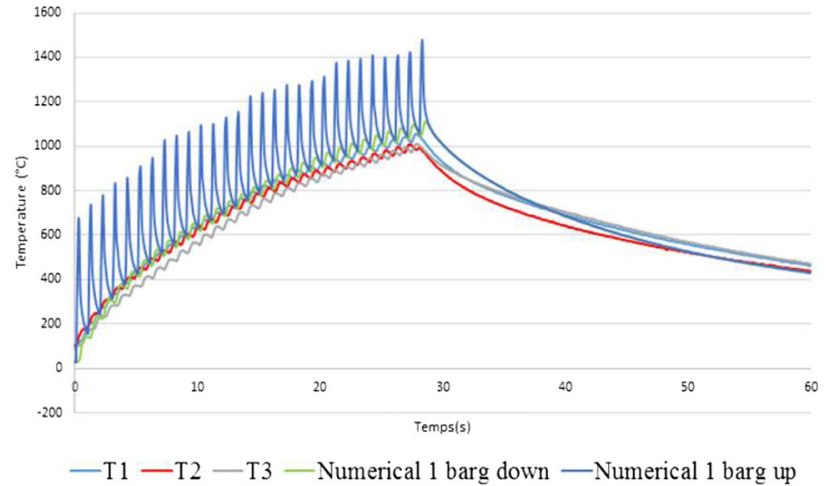

(a)

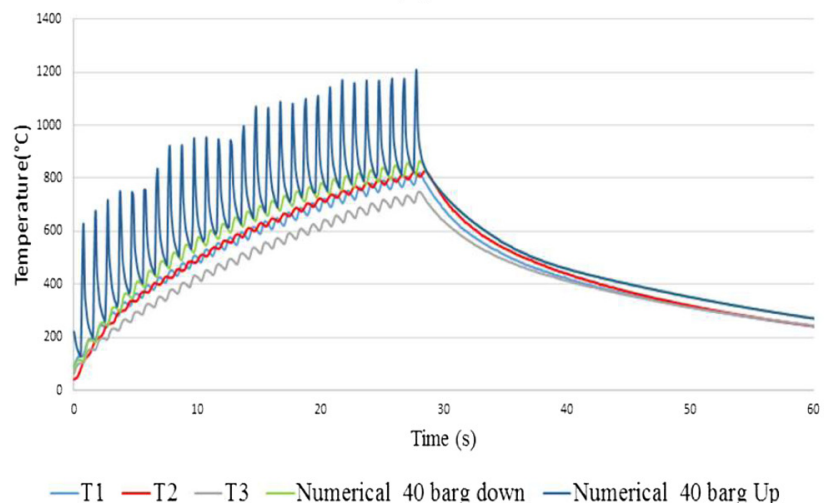

(b)

FIG. 7. Comparison of numerical and experimental curves for stainless steel 310. "Down" stands for sample's back side, and "Up" stands for the front side. (a) At 1 barg oxygen; (b) at 40 barg oxygen.

temperature correspond to the temperature seen by thermocouples during the laser spot rotary movement.

For both types of experiments, the cooling rate after 30 or $1800 \mathrm{~s}$ was determined for three ranges of temperature, i.e., $800-600^{\circ} \mathrm{C}$, $600-400^{\circ} \mathrm{C}$, and $400-200^{\circ} \mathrm{C}$. Results summarized in Table IV show a significant difference in the cooling rate, between 1 and 40 barg experiments as well between 30 and 1800 s experiments.

The observed cooling rate is lower for experiments with a long preheating as the thermal losses heat the sample holder. Numerical approach (presented hereafter) was useful for a better understanding of such behaviors.

\section{B. Numerical approach}

Using COMSOL MULTIPHYSICS software, we have proceeded to a thermal analysis of our sample until its melting point, including preheating and cooling steps. Figure 8 shows the different domains we have defined. The "r6" and "uni1" are defined as copper parts, with density, conductivity, and heat capacity taken constant. The " $\mathrm{r} 3$ " and " $\mathrm{r} 5$ " are defined as Mica parts, with an anisotropic conductivity 
TABLE IV. Cooling rate depending on the heating duration (30 and $1800 \mathrm{~s}$ ) and oxygen pressure for stainless steel 310 .

\begin{tabular}{lccc}
\hline \hline $\begin{array}{l}\text { Cooling rate } \\
\left({ }^{\circ} \mathrm{C} / \mathrm{s}\right)\end{array}$ & $800-600{ }^{\circ} \mathrm{C}$ & $600-400{ }^{\circ} \mathrm{C}$ & $400-200{ }^{\circ} \mathrm{C}$ \\
\hline $1800 \mathrm{~s}, 1$ barg & $16 \pm 1$ & $7 \pm 0.5$ & $2.9 \pm 0.5$ \\
$1800 \mathrm{~s}, 40$ barg & $25 \pm 1$ & $13 \pm 0.5$ & $6 \pm 0.5$ \\
$30 \mathrm{~s}, 1$ barg & $18 \pm 5$ & $12 \pm 1$ & $4 \pm 1$ \\
$30 \mathrm{~s}, 40$ barg & $50 \pm 5$ & $25 \pm 1$ & $8 \pm 1$ \\
\hline \hline
\end{tabular}

(variable from 0.7 to $2.0 \mathrm{~W} \mathrm{~m}^{-1} \mathrm{~K}^{-1}$ ) along $\mathrm{Z}$ axis and $3.0 \mathrm{~W} \mathrm{~m}^{-1} \mathrm{~K}^{-1}$ in the XY plane. The "r4" stands for the sample.

Data from Mills ${ }^{7}$ were used for density, conductivity, and heat capacity as a function of the temperature. Time dependent model with a moving laser spot needs a complete $3 \mathrm{D}$ model. For example, Fig. 9 shows the thermal field on the top side of the sample (oxygen side) generated by the moving laser spot. With an optimized meshing, a computation needs about $1 \mathrm{~h}$ for $30 \mathrm{~s}$ heating and $70 \mathrm{~s}$ cooling. Computations on long heating (1800 s) were not needed. We focused on heating and cooling phase.

\section{Effect of temperature on thermal losses}

Data found up to $600 \mathrm{~K}$ show that the thermal conductivity of gaseous oxygen is strongly dependent on temperature, but almost independent of pressure. ${ }^{8,9}$ To fit numerical results with experimental ones, we have chosen to add a temperature dependence on the two following parameters. First, we considered the heat exchange convection factor as dependent on the sample temperature. As the gas in the vicinity of the sample is static and heated up by contact with the sample, the thermal exchange gas/ sample is evolving due to the evolution of heat conductivity of oxygen with temperature. Nevertheless, the adaptation of the heat exchange coefficient as a function of temperature does not allow obtaining a correct fit between calculated and measured cooling rates. Consequently, we tested the hypothesis of evolution of the thermal behavior of Mica seal with temperature. An "equivalent conductivity" of Mica seal was used along the $\mathrm{Z}$ axis.

As the sample is pressed onto the Mica seal to avoid oxygen leakage under pressurized tests, an increase in pressure on the

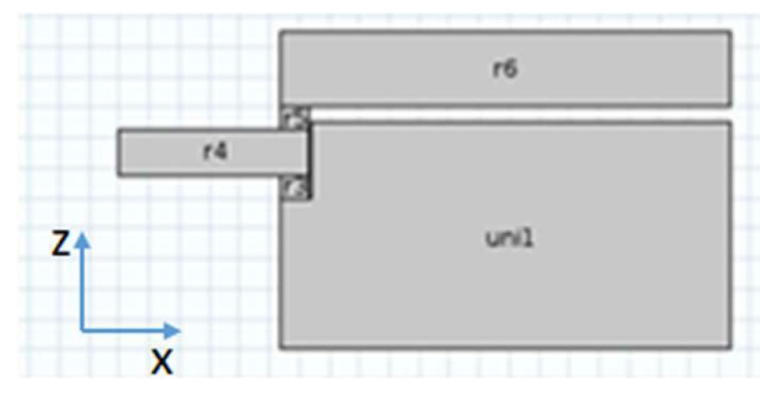

FIG. 8. Domains definition for modeling.

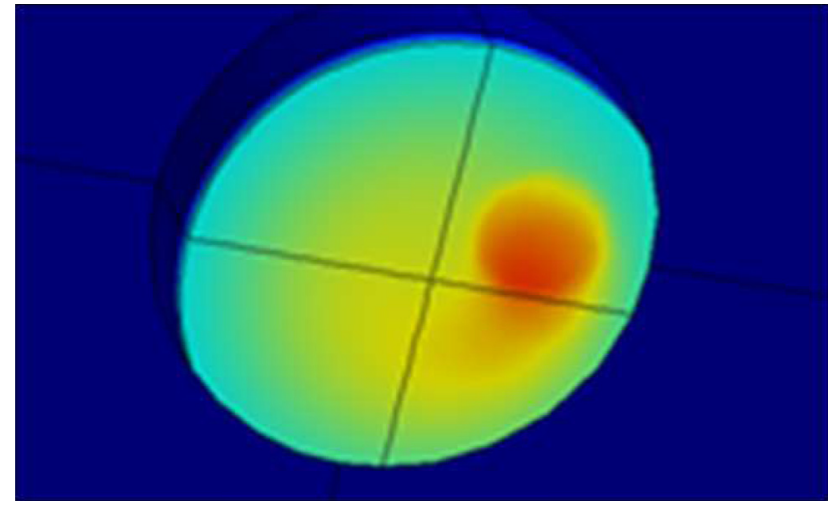

FIG. 9. Temperature field on the surface of the sample, after $28 \mathrm{~s}$ of heating, stainless steel 310 .

sample probably affects the thermal conductivity along the $\mathrm{Z}$ axis of Mica seal. Mica is an assembly of thin layers, with a thermal resistance between each layer, and a contact resistance between the seal and the sample, as well as between the seal and the copper support. Moreover, an increase of temperature of the sample induces its thermal expansion. For example, a thermal variation of $1000 \mathrm{~K}$ will induce an increase of $50 \mu \mathrm{m}$ in the thickness direction of a $3 \mathrm{~mm}$ thick sample (and about $400 \mu \mathrm{m}$ in its diameter direction).

To sum up, we have to adjust our equivalent parameters "thermal exchange gas/sample" and "equivalent conductivity of Mica seal" as a function of pressure and temperature-for conductive heat transfer, we choose a quite linear variation from 30 to $70 \mathrm{~W} \mathrm{~m}^{2} \mathrm{~K}$ in the range $300-1000 \mathrm{~K}$. As this factor is multiplied by 2.5 in this temperature range, it is comparable with the evolution of the thermal conductivity of air and oxygen for the same range of temperature (Table V). We can consider that higher pressures contribute to reduce the thermal contact resistance, even at relatively low temperature. Consequently, the equivalent conductivity of Mica seal was increased for a higher pressure (Table V).

For a 40 barg experiment in oxygen, similar laser parameters lead to a lower maximum temperature (delta of about $200^{\circ} \mathrm{C}$ ) and a higher cooling rate (Table IV). This result observed on all experiments (decade of them) is consistent with the evolution of the thermal losses at high temperature and under high pressure.

An estimation of the upper side sample temperature (oxygen side) including the local temperature increase under the laser spot was calculated using the developed numerical model-on the upper side, the maximum temperature can reach locally, under the laser

TABLE V. Convective heat transfer and Mica's equivalent thermal conductivity used for 1 and 40 barg simulations.

\begin{tabular}{lcc}
\hline \hline & $\begin{array}{c}\text { Convective heat transfer } \\
\left(\mathrm{W} \mathrm{m}^{2} \mathrm{~K}\right)\end{array}$ & $\begin{array}{c}\text { Mica's thermal conductivity } \\
\left(\mathrm{W} \mathrm{m}^{-1} \mathrm{~K}^{-1}\right)\end{array}$ \\
\hline 1 barg & 30 & $0.6-2.2$ \\
$40 \mathrm{barg}$ & $30-70$ & $0.7-2.2$ \\
\hline \hline
\end{tabular}



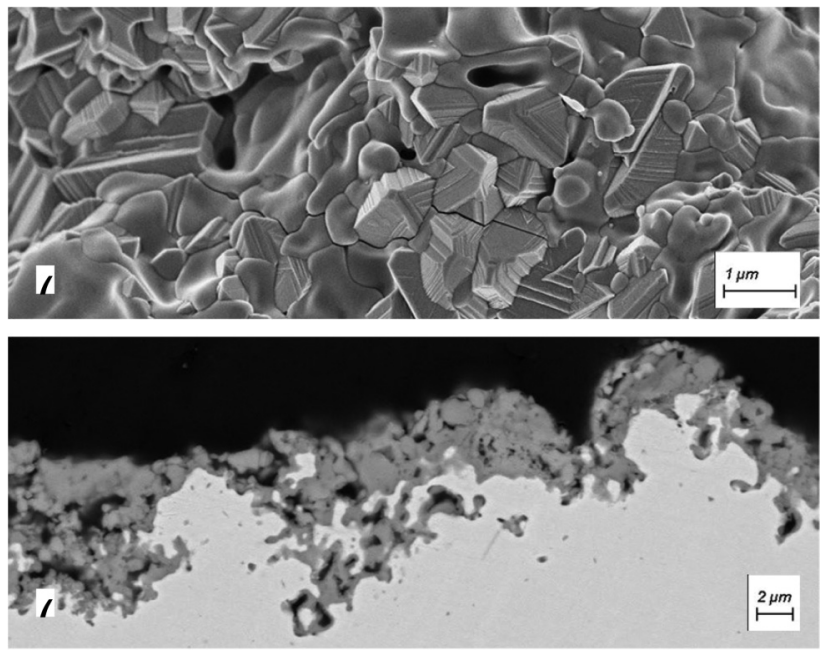

FIG. 10. Partial melting of stainless steel 310 at laser spot trajectory—oxidized samples during $900 \mathrm{~s}$ in pure oxygen at 40 barg. (a) Surface; (b) cross section.

beam, for a very short time, a peak temperature of about $300^{\circ} \mathrm{C}$ higher than on the back side of the sample despite the mean temperature on the sample back side (air side) remains under a maximum value of about $1000^{\circ} \mathrm{C}$.

This result is consistent with metallographic observations showing a partial melting in the area of laser spot trajectory as shown at Fig. 10 for stainless steel 310 (melting temperature $1400-1450^{\circ} \mathrm{C}$ ).

\section{OXIDE LAYERS CHARACTERIZATIONS}

Oxide layers were characterized also in terms of thickness, morphology, and chemical composition. For metallographic analysis, samples were first protected by GATAN resin in order to protect the surface oxide layer and cut with a Secotom-50 Struers tabletop cutoff machine. Then, samples were vacuum coated with an epoxy resin and polished with PRESI SiC foils (grit 600-2400) followed by diamond polishing (grain size: $3-1 \mu \mathrm{m}$ ).

The surface of the sample was analyzed with an InLens detector on a ZEISS Ultra 55 scanning electron microscope (SEM). The cross section was analyzed with an AXS Bruker energy dispersive spectrometer. The determination of crystalline phases was done by x-ray diffraction (XRD) on a Miniflex II Rigaku diffractometer

TABLE VI. Mass gain (average from two samples \pm std deviation). Samples oxidized in air at $850^{\circ} \mathrm{C}$ and atmospheric pressure, during 93,213 , and $332 \mathrm{~h}$.

\begin{tabular}{lccc}
\hline \hline $\begin{array}{l}\text { Mass gain } \\
\left(\mathrm{mg} / \mathrm{cm}^{2}\right)\end{array}$ & $95 \mathrm{~h}$ & $213 \mathrm{~h}$ & $332 \mathrm{~h}$ \\
\hline Stainless & $0.5663 \pm 0.0254$ & $0.7170 \pm 0.0127$ & $0.9470 \pm 0.0111$ \\
steel 310 & \multicolumn{3}{c}{} \\
IN600 & \multicolumn{2}{c}{ Not measured } & $0.4307 \pm 0.0712$ \\
IN625 & & $0.4722 \pm 0.0005$ \\
\hline
\end{tabular}

TABLE VII. Oxide thickness (average from six measurements \pm std deviation). Samples oxidized in air at $850^{\circ} \mathrm{C}$ and atmospheric pressure, during 93,213 , and $332 \mathrm{~h}$.

\begin{tabular}{lccc}
\hline \hline $\begin{array}{l}\text { Thickness } \\
(\mu \mathrm{m})\end{array}$ & $95 \mathrm{~h}$ & $213 \mathrm{~h}$ & $332 \mathrm{~h}$ \\
\hline Stainless steel 310 & $2.7 \pm 0.5$ & $3.3 \pm 0.3$ & $3.4 \pm 0.1$ \\
IN600 & Not measured & $1.8 \pm 0.4$ \\
IN625 & & $2.4 \pm 0.7$ \\
\hline
\end{tabular}

equipped with a $\mathrm{Cu}$ tube and a $\mathrm{D} /$ teX detector. XRD patterns were performed between $10^{\circ}$ and $120^{\circ}(2 \theta)$ in $\theta-2 \theta$ configuration on massive samples.

\section{A. Oxides formed during preheating in furnace in air at atmospheric pressure and $850{ }^{\circ} \mathrm{C}$}

In order to compare oxide layers formed during laser oxidation in the pure oxygen atmosphere (at 1 and $40 \mathrm{barg}$ ) with those formed in ambient air (1 bara) at the same temperature, a 601 Nabertherm heat treatment furnace was used, with a static air atmosphere.
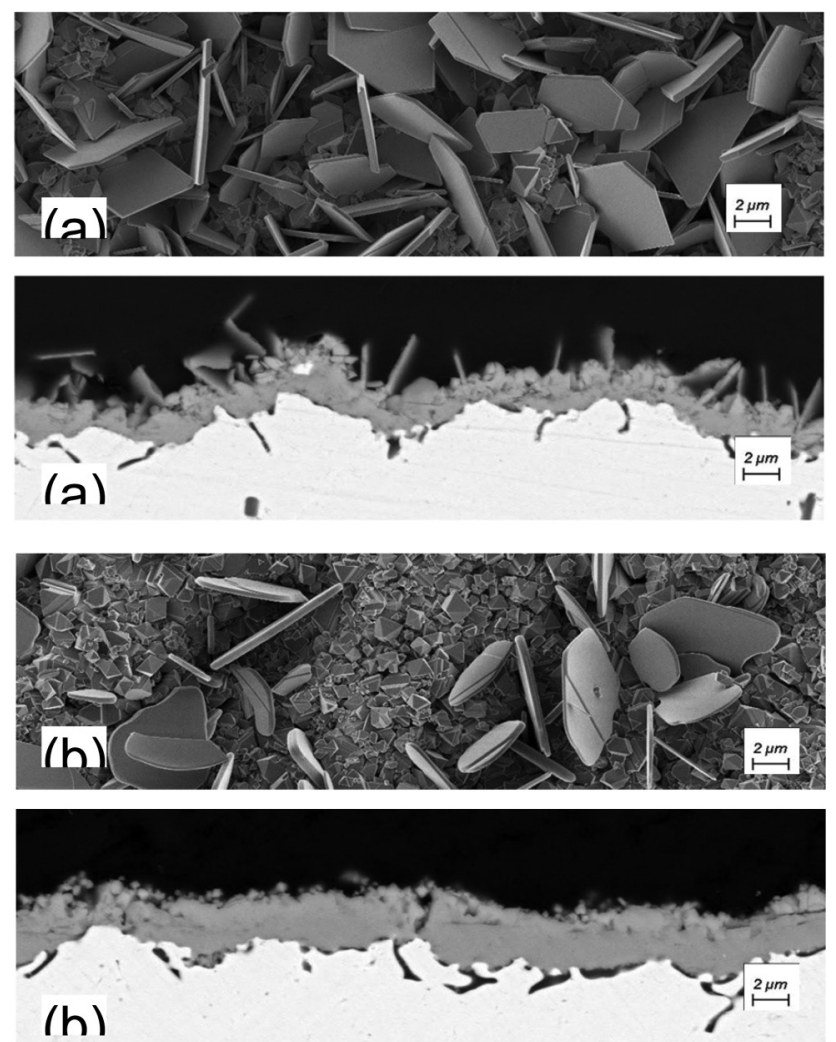

FIG. 11. Morphology of oxides formed on stainless steel 310 on the surface (top photo) and below the surface (bottom) after oxidation in air at $850^{\circ} \mathrm{C}$ and atmospheric pressure, during (a) $93 \mathrm{~h}$; (b) $332 \mathrm{~h}$. 

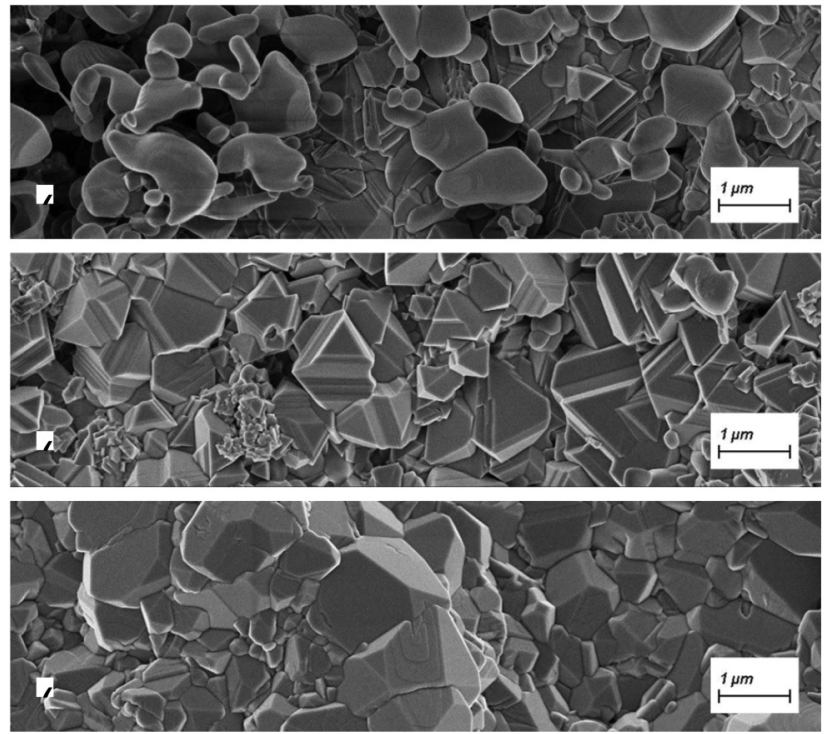

FIG. 12. Morphology of oxides formed on the surface of Inconels after oxidation in air at $850^{\circ} \mathrm{C}$ and atm. pressure, during $332 \mathrm{~h}$. (a) and (b) Inconel 600; (c) Inconel 625.

Stainless steel 310 samples mass gain was checked after 95, 213, and $332 \mathrm{~h}$. The mass gain of Inconels 600 and 625 was checked after 332 $\mathrm{h}$ of exposure. As expected, results summarized in Table VI show a slower mass gain for Inconels compare to stainless steel 310 . The oxide thickness follows a similar trend as resumed in Table VII.

Morphology of oxides observed both on the sample surface and on the metallographic cut perpendicularly to the surface is presented for stainless steel 310 and Inconels, respectively, in Figs. 11 and 12 , and the corresponding $\mathrm{XRD}$ analyses are shown in

TABLE VIII. XRD analyses done on the surface of the sample showing the principal indexed compounds. Integrate both zones inside and outside of the laser spot trajectory.

\begin{tabular}{|c|c|c|}
\hline $\begin{array}{l}\text { Stainless steel } 310 \\
\text { Furnace }(332 \mathrm{~h}) \\
\text { Base metal } \mathrm{Cr}_{2} \mathrm{O}_{3} \text {; } \\
\mathrm{Fe}_{3} \mathrm{O}_{4}\end{array}$ & $\begin{array}{l}\text { Stainless steel } 310 \\
1 \text { bar }(900 \mathrm{~s}) \\
\text { Base metal } \mathrm{Cr}_{2} \mathrm{O}_{3} ; \\
\mathrm{Fe}_{3} \mathrm{O}_{4}\end{array}$ & $\begin{array}{l}\text { Stainless steel } 310 \\
40 \text { bar }(900 \mathrm{~s}) \\
\text { Base metal } \mathrm{Cr}_{2} \mathrm{O}_{3} ; \\
\mathrm{Fe}_{3} \mathrm{O}_{4}\end{array}$ \\
\hline $\begin{array}{l}\text { Inco } 600 \\
\text { Furnace }(332 \mathrm{~h}) \\
\text { Base metal } \mathrm{Cr}_{2} \mathrm{O}_{3} \\
\mathrm{AB}_{2} \mathrm{O}_{4} \text { or } \mathrm{A}_{3} \mathrm{O}_{4}+ \\
\text { unindexed peaks }\end{array}$ & $\begin{array}{c}\text { Inco } 600 \\
1 \text { bar }(900 \mathrm{~s}) \\
\text { Base metal } \mathrm{Cr}_{2} \mathrm{O}_{3} \\
\mathrm{AB}_{2} \mathrm{O}_{4} \text { or } \mathrm{A}_{3} \mathrm{O}_{4}\end{array}$ & $\begin{array}{c}\text { Inco } 600 \\
40 \text { bar }(900 \mathrm{~s}) \\
\text { Base metal } \mathrm{NiO} \\
\mathrm{Cr}_{2} \mathrm{O}_{3} \mathrm{AB}_{2} \mathrm{O}_{4} \text { or } \\
\mathrm{A}_{3} \mathrm{O}_{4}\end{array}$ \\
\hline $\begin{array}{l}\text { Inco } 625 \\
\text { Furnace }(332 \mathrm{~h}) \\
\text { Base metal } \mathrm{Cr}_{2} \mathrm{O}_{3} \\
\mathrm{NbNi}_{3}\end{array}$ & $\begin{array}{c}\text { Inco } 625 \\
1 \text { bar }(900 \mathrm{~s}) \\
\text { Base metal } \mathrm{Cr}_{2} \mathrm{O}_{3} \\
\mathrm{AB}_{2} \mathrm{O}_{4} \text { or } \mathrm{A}_{3} \mathrm{O}_{4}+ \\
\text { unindexed peaks }\end{array}$ & $\begin{array}{c}\text { Inco } 625 \\
40 \text { bar }(900 \mathrm{~s}) \\
\text { Base metal } \mathrm{NiO} \\
\mathrm{AB}_{2} \mathrm{O}_{4} \text { or } \mathrm{A}_{3} \mathrm{O}_{4} \\
\mathrm{Cr}_{2} \mathrm{O}_{3}+\text { unindexed } \\
\text { peaks }\end{array}$ \\
\hline
\end{tabular}
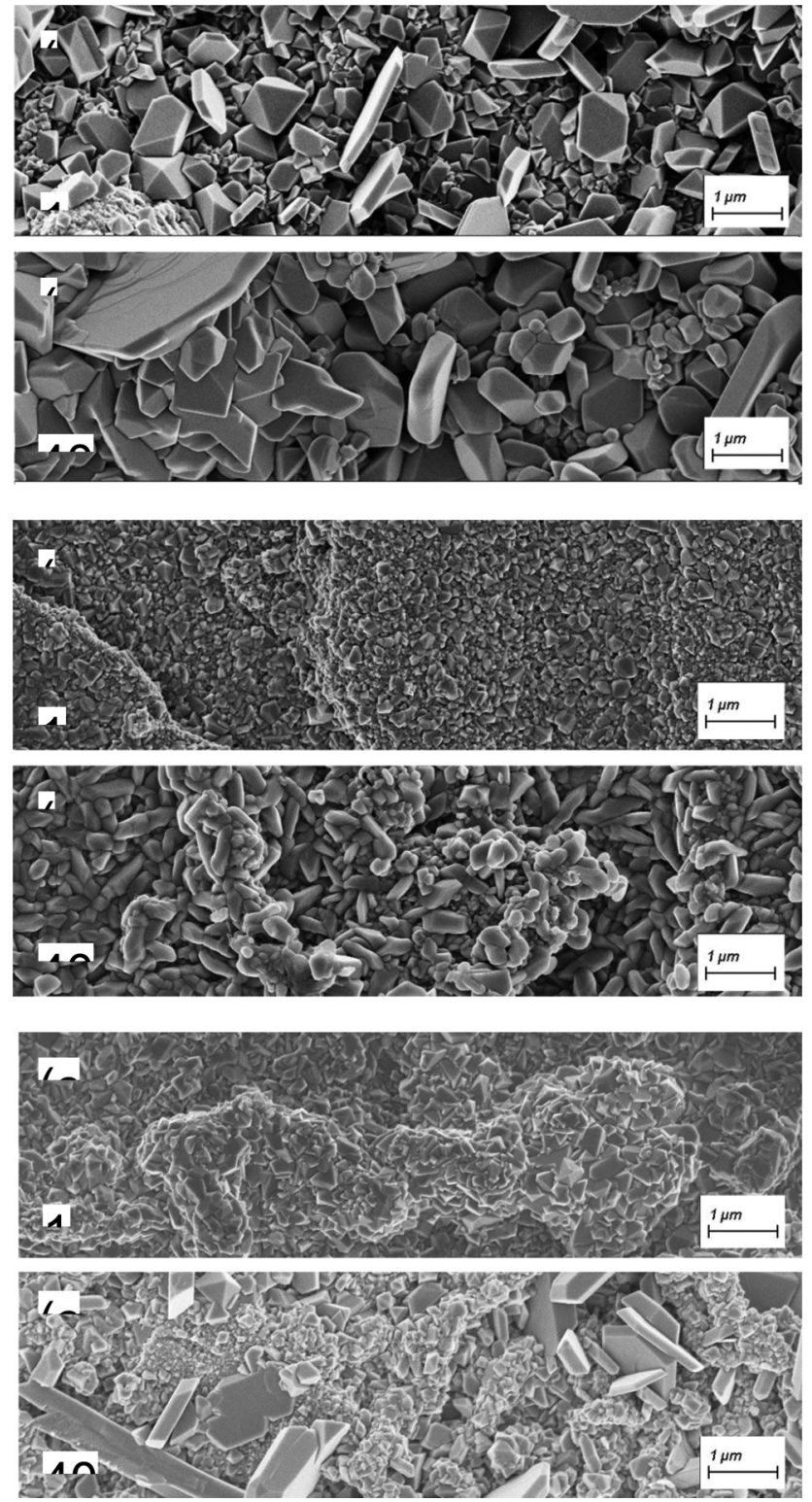

FIG. 13. Morphology of oxides formed at the surface of laser oxidized samples (zone in the center of sample, i.e., outside of laser spot trajectory) during $900 \mathrm{~s}$ in the pure oxygen atmosphere at 1 barg (top) and 40 barg (down). (a) Stainless steel 310; (b) Inconel 600; (c) Inconel 625.

Table VIII. For stainless steel 310, after $332 \mathrm{~h}$ of exposure to air at $850^{\circ} \mathrm{C}$, the oxide layer is composed of a continuous layer of oxide composed by a mixture of chromium oxide $\left(\mathrm{Cr}_{2} \mathrm{O}_{3}\right)$ with a sharptype morphology and of iron oxide $\left(\mathrm{Fe}_{3} \mathrm{O}_{4}\right)$ having a plate-type morphology. One observes a sharp increase in chromium oxide between 95 and $332 \mathrm{~h}$ exposure time (Fig. 11).

For Inconel 600 , after $332 \mathrm{~h}$ of exposure to air at $850^{\circ} \mathrm{C}$, two types of morphologies were observed as well [Figs. 12(a) and 12(b)]: 
chromium oxide $\left(\mathrm{Cr}_{2} \mathrm{O}_{3}\right)$ as in the case of stainless steel 310 and an $\mathrm{AB}_{2} \mathrm{O}_{4}$ or $\mathrm{A}_{3} \mathrm{O}_{4}$ type globular compound. According to Ref. 10, this phase could be a mixture of $\mathrm{NiO}$ and $\mathrm{Cr}_{2} \mathrm{O}_{3}$ oxides or a spinel $\mathrm{NiFe}_{2} \mathrm{O}_{4} \cdot{ }^{11}$ In the case of Inconel 625 , the oxide layer is principally composed of chromium oxide with an underlying layer of $\mathrm{Ni}_{3} \mathrm{Nb}$.

\section{B. Oxides formed by laser preheating in pure oxygen at pressure 1 and $\mathbf{4 0}$ barg}

A comparison of oxide layers' morphology formed on three studied materials after a $900 \mathrm{~s}$ laser oxidation in the pure oxygen atmosphere at 1 and 40 barg is presented in Fig. 13. Corresponding XRD analyses are shown in Table VIII. One can observe that the morphology of laser oxidized samples at 40 barg is close to that observed at 1 barg oxygen. Nevertheless, two differences are to be noticed.

First, at 40 barg oxygen, the phases have a coarser morphology (in both areas: inside and outside the laser spot trajectory) and oxide layers present a higher thickness (especially inside the laser spot trajectory). For example, for stainless steel 310, the maximum oxide thickness inside the spot trajectory was $0.5 \mu \mathrm{m}$ at 1 barg and $3.9 \mu \mathrm{m}$ at $40 \mathrm{barg}$. This phenomenon is to be linked to the higher oxidation kinetics expected at 40 barg and to the overheating predicted by the preheating model in the zone below the laser spot.

Second, the relative quantity of chromium oxide seems to be decreasing for 40 barg oxygen experiments. This result is probably a consequence of the aforementioned overheating occurring below the laser spot, especially at 40 barg. In that zone, according to Ref. 12, the sample temperature was situated in the domain of a thermal instability of chromium oxide. As the XRD surface analysis integrates both areas inside and outside of laser trajectory, the resulting chromium oxide quantity appears as decreasing after oxidation at 40 barg.

The comparison between the oxides morphology observed in the center of laser oxidized samples and those oxidized in air shows very consistent results.

\section{CONCLUSIONS}

This work, a preliminary step required for the studying of metals' ignition and combustion under the pure oxygen atmosphere, has allowed the defining of an experimental setup and procedure for the creation of controlled oxide layers in a pure pressurized oxygen atmosphere.

A numerical approach brought a better understanding of the thermal losses involved in experiments carried out in 40 barg oxygen static atmosphere and was useful for optimization of preheating parameters in such operating conditions.

The use of a moving laser spot, with a $5.6 \mathrm{~mm}$ diameter, allowed a good homogenization of sample temperature for preheating to $850^{\circ} \mathrm{C}$, but for higher preheating temperature, melting temperature of the sample could be locally reached at the laser spot trajectory. The center of the sample, not concerned by this phenomenon, presents a surface morphology similar to that obtained after furnace oxidation at $850^{\circ} \mathrm{C}$. Given that the ignition resistance tests are performed in the center of the sample, we can consider that used preheating cycle allows one to create an oxidation layer representative to that existing on industrial components in the hot oxygen service.

An alternate solution, using a larger spot, is under study, in order to decrease the thermal gap between both sides of the sample and to avoid reaching the melting temperature at the laser spot trajectory.

\section{ACKNOWLEDGMENT}

The authors' acknowledgement goes to Caroline Bertail, Air Liquide R\&D, for XRD analysis.

\section{REFERENCES}

${ }^{1}$ M. Muller, R. Fabbro, H. El-Rabii, and K. Hirano, “Temperature measurement of laser heated metals in highly oxidizing environment using $2 \mathrm{D}$ single-band and spectral pyrometry," J. Laser Appl. 24, 022006 (2012).

${ }^{2}$ Gary D. Greenblatt, John J. Orlando, James B. Burkholder, and A. R. Ravishankara, "Absorption measurements of oxygen between 330 and 1140nm,” J. Geophys. Res. 95, 18577-18582 (1990).

${ }^{3}$ M. Muller, Study on Processes of Ignition by Laser of Combustion of Metallic Alloy Under Pure Oxygen Atmosphere (Ecole Nationale Supérieure de Mécanique et d'Aéronautique, Poitiers, 2013).

${ }^{4}$ M. Muller, H. El-Rabii, R. Fabbro, F. Coste, J.-C. Ostaing, M. Ridlova, A. Colson, and H. Barthélémy, "Detailed investigation of the sequence of mechanisms participating in metals ignition in oxygen using laser heating and in situ, real-time diagnostics," in ASTM STP 1596, Flammability and Sensitivity of Materials in Oxygen-Enriched Atmospheres: 14th Volume, edited by S. Davis and T. Steinberg (ASTM International, West Conshohocken, PA, 2016), pp. 308-325. ${ }^{5}$ M. Schneider, L. Berthe, R. Fabbro, and M. Muller, "Measurement of laser absorptivity for operating parameters characteristic of laser drilling regime," J. Phys. D Appl. Phys. 41, 155502 (2008).

${ }^{6}$ N. K. Tolochko, Yu. V. Khlopkov, S. E. Mozzharov, N. V. Sobolenko, and I. A. Yadroitsev, "Measurement of the absorption coefficient of freely poured one-component metallic powders and its change during laser sintering," Powder Metall. Met. Ceram. 36, 433-437 (1997).

${ }^{7}$ K. C. Mills, Recommended Values of Thermophysical Properties for Selected Commercial Alloys (Woodhead, Cambridge, 2002).

${ }^{8}$ M. L. Huber and A. H. Harvey, Thermal Conductivity of Gases, CRC Handbook of Chemistry and Physics (CRC, Boca Raton, 2011), pp. 6-240, 6-241.

${ }^{9} \mathrm{E}$. W. Lemmon and R. T. Jacobsen, "Viscosity and thermal conductivity equations for nitrogen, oxygen, argon, and air," Int. J. Thermophys. 25, 21-69 (2004).

${ }^{10} \mathrm{~J}$. Moreau and J. Pouligner-Bernard, L'Oxydation Des Métaux (Gauthiers-Villars, Paris, 1964).

${ }^{11}$ R. Wallwork and J. Croll, "The high-temperature oxidation of iron-chromiumnickel alloys containing 0-30\% chromium,” Oxid. Met. 4, 121-140 (1972).

${ }^{12}$ H. D. Beeson, W. F. Stewart and S. S. Woods, "Safe use of oxygen and oxygen systems: Guidelines for oxygen system design, materials selection, operations, storage, and transportation," in ASTM Manual Series: MNL36, Handbook for Design, Operation, and Maintenance: 2nd Edition (ASTM International, West Conshohocken, PA, 2007).

\section{Meet the Author}

Frédéric Coste works on high power laser application (welding, cutting, surface treatment) since 1990 . He focuses currently on characterization of material property at high temperature and combustion of metallic material under the pure oxygen atmosphere. 